\title{
Demography and Feeding Practices of ICU Patient of Government and Private Hospitals of Jorhat District, Assam
}

\author{
Bordoloi PL, Barooah MS, M. Gogoi \\ Department of Food Science and Nutrition, College of Home Science, Jorhat, Assam, India
}

\begin{tabular}{l}
\hline Article Info \\
\hline Article history: \\
Received Sep 13, 2017 \\
Revised Nov 17, 2017 \\
Accepted Dec 2, 2017
\end{tabular}

\section{Keyword:}

Feeding practices Intensive care unit Length of stay

Patient demographic

\begin{abstract}
The aim of the present study was to analyze the characteristics and feeding practices of patient admitted to medicine ICUs. All relevant clinical and dietary information were collected for patients admitted to ICUs of selected Government and private hospitals of Jorhat district, Assam. This information was abstracted with the help of pre - structured schedule from the Medical Record Department and Intensive Care Unit team and analysed. A total of 1034 patients were admitted during the study period. Majority of the patients $(49.61 \%)$ were from the age group of 60years and above. Majority incidence of diseases is a reason of admission in ICUs of both the hospitals was noncommunicable diseases and patients were admitted via emergency OPD. Highest length of stay of 10-15days was observed among the majority of patient from government hospital while it was shorter (6-10days) for private hospital. The daily feeding pattern of each of the patients was recorded. Patients dependent on homemade blenderized foods for nutritional support were more in Government hospital while compare to the patient using both the commercial formulae as well as homemade food till the last day of stay in private hospitals. Increased cost of hospitalization and better outcome of patient in terms of short stay at hospitals and better nutritional status of the patient admitted to private hospitals were not feasible for low income groups patients admitted in Government hospital. The results of the present study will help the need of formulation and development of patient specific homemade foods with its ingredients used and nutritional requirement in it are taken account for both oral and enteral feedings in the hospitals with higher standard values with all demonstration on the development of protocols for clean techniques in the preparation, safe handling and storage of handmade enteral feeds.
\end{abstract}

Copyright $@ 2017$ Institute of Advanced Engineering and Science. All rights reserved.

\section{Corresponding Author:}

Moloya Gogoi,

Assistant Professor, Department of Food Science and Nutrition,

College of Home Science, Assam Agricultural University,

Jorhat-785013, India, mobile no: 07086893911.

Email: moloyagogoi02@gmail.com

\section{INTRODUCTION}

Patients Intensive Care Unit (ICU); Patient demographic; Length of stay; Feeding practices admitted in ICUs have complex nutritional needs and require intensive and nutritional input which becomes a large and expensive component of modern health care [1]-[4]. Nutritional therapy plays an important role in overall outcome of the patients. It functions on providing the best nutritional support aimed at individualized short-term beneficial effects of the stress response to injury or illness, and to minimize the long-term harmful consequences of malnutrition due to insufficient nutrition during the stay.

In ICU, patients are treated with life supporting treatment including therapeutic diet under intensive monitoring .Advancement in the care of patients has been associated with a significant increase usages of a 
large number of both commercial formulae and homemade enteral diets as nutritional support for hospitalized patients with different conditions. This study will identify and help to develop a database on various patient related information including patient demography and characteristics together with the details on diagnosis, length of stay in the ICU and feeding practices during the stay for both the Government as well as private hospitals and will give towards insight into the need of ensuring proper health care with proper nutritional support.

\section{RESEARCH METHOD}

A retrospective study was conducted in the medical intensive unit of Jorhat Medical College \& Hospital (JMCH), a government hospital and the private hospital namely Jorhat Christian Medical Centre (JCMC), Jorhat, Assam, catering to the population of nearby areas of Jorhat district. A clinical database of all the consecutive admission to medicine ICUs of both the hospitals were collected for a period of 6 months from October 2015 to April 2016. Patients were admitted either from the emergency unit, from another wards or referred from other hospitals .Data were collected from the medical record department, ICU logbook and patient medical records with the help of a pre-structured schedule. For each patient, information on baseline demographic data, together with details on diagnosis, date of ICU admission, primary reasons for the admission, underlying disease and survival status (death or discharge from ICUs) were recorded. The feeding practices in the ICUs from the day of admission till the day of discharge were recorded. At the end, length of stay (LOS) at ICUs was assessed as the number of days from admission to the ICU to discharge from the ICU.

\subsection{Statistical analysis}

Descriptive analysis of the salient factors resulting in admission to ICUs and dietary related information were described in terms of mean and standard deviation and range. Categorical variables were expressed as actual number and percentage.

\section{RESULTS AND DISCUSSION}

During the study period, 1034 patients were admitted to ICU comprising 169 numbers of patients from Jorhat Medical College and Hospital (JMCH) and 865 from Jorhat Christian Medical Centre (JCMC), Jorhat, Assam. Sixty three percent were male while $37 \%$ were female being a ratio of male to female 1:06. This observation is in line with reports from other studies [5]-[7]. The mean age of the total population was $58.92+13.89$ years covering a age ranges from 14 to 102 years while results from different studies revealed lower mean age [5],[8] as well as higher mean age [6],[8],[9]. Table 1 shows that almost fifty three percent of the total population were aged between $40-60$ years, $49.61 \%$ aged 60years and above and $13.44 \%$ between the age group of 20-40 years. Very less number of patient in the age strata of 5-20 years in both the hospitals were observed. The major religion of patients were Hindu (84.62\%) followed by Muslim (4.54\%) and other $(10.83 \%)$ respectively.

Table 1. Demographic of Patient Admitted to JMCH and JCMC According to the Age

\begin{tabular}{|c|c|c|c|c|c|c|}
\hline \multirow[t]{2}{*}{ Age strata/Hospital } & \multicolumn{2}{|c|}{$\begin{array}{l}\text { Jorhat Medical College \& } \\
\text { Hospital (Govt. Hospital) }\end{array}$} & \multicolumn{2}{|c|}{$\begin{array}{l}\text { Jorhat Christian Medical } \\
\text { Centre (Private Nursing) }\end{array}$} & \multicolumn{2}{|c|}{ Total } \\
\hline & $\mathrm{n}$ & $\%$ & $\mathrm{n}$ & $\%$ & $\mathrm{n}$ & $\%$ \\
\hline \multicolumn{7}{|l|}{ Sex } \\
\hline Male & 103 & 60.94 & 544 & 62.89 & 647 & 62.57 \\
\hline Female & 66 & 39.06 & 321 & 37.10 & 387 & 37.42 \\
\hline \multicolumn{7}{|l|}{ Age } \\
\hline 60 -and above & 54 & 31.95 & 459 & 53.06 & 513 & 49.61 \\
\hline $40-60$ yrs. & 67 & 39.64 & 280 & 32.37 & 347 & 53.35 \\
\hline $20-40$ yrs. & 35 & 20.71 & 104 & 12.02 & 139 & 13.44 \\
\hline $5-20$ yrs. & 13 & 7.69 & 5 & 1.73 & 28 & 2.7 \\
\hline \multicolumn{7}{|l|}{ Race/Religion } \\
\hline Hindu & 123 & 72.78 & 752 & 86.93 & 875 & 84.62 \\
\hline Muslim & 26 & 15.38 & 21 & 2.43 & 47 & 4.54 \\
\hline Others & 20 & 11.83 & 92 & 10.63 & 112 & 10.83 \\
\hline
\end{tabular}

Most patients (79.89\%) were admitted from outpatient clinic while $20.30 \%$ were from general hospital wards and referred from different hospitals. About $90 \%$ of the population were referred from the emergency department, $4 \%$ were from the hospitals wards and $6 \%$ were from referred from other hospitals 
.Distribution of patients according to the diagnoses on admission is given in Table 2. Diabetes mellitus alone and with complication was found highest among $511(49.42 \%)$ followed by cardiac diseases $221(21.00 \%)$, acute respiratory failure $197(19.00 \%)$ while very few cases of poisoning $(1.16 \%)$ and infectious diseases $(1.35 \%)$ were recorded.

Table 2. Distribution of Patients According to the Diagnoses on Admission

\begin{tabular}{|c|c|c|c|c|}
\hline \multirow{2}{*}{ Diseases diagnoses at the time of admission } & \multirow{2}{*}{$\begin{array}{c}\text { Jorhat Medical College } \\
\text { Hospital }(n=169)\end{array}$} & \multirow{2}{*}{$\begin{array}{c}\text { Jorhat Christian Medical } \\
\text { Centre }(n=865)\end{array}$} & \multicolumn{2}{|c|}{ Total $(\mathrm{N}=1034)$} \\
\hline & & & $\mathrm{n}$ & $\%$ \\
\hline Acute respiratory failure & 51 & 146 & 197 & 19.00 \\
\hline Cardiac diseases & 26 & 195 & 221 & 21.00 \\
\hline Acute $\&$ chronic renal failure & 3 & 17 & 20 & 1.93 \\
\hline Diabetic and diabetic with complications & 59 & 452 & 511 & 49.42 \\
\hline Neurological diseases & 2 & 3 & 5 & 0.48 \\
\hline Infectious diseases & 9 & 5 & 14 & 1.35 \\
\hline Accidents & 8 & 13 & 21 & 2.03 \\
\hline Poisoning & 5 & 7 & 12 & 1.16 \\
\hline Others & 6 & 27 & 33 & 3.19 \\
\hline
\end{tabular}

Record on feeding practices of each patient during their stay in ICUs were evaluated and found that indication of artificial feeding within 24 hours of ICU admission in both the ICUs of government and private hospitals were common to majority of patient while very less could take orally. Distribution of patients according to the feeding practices is given in Table 3. Seven hundred and twenty two patients out of 1034 were fed both the homemade and commercially available formulae of which 95.29 per cent of patients were from Jorhat Christian Medical Centre only. Usage of only homemade blenderdised food as nutritional support for both the oral and enteral feeding was seen highest in JMCH (75.15\%) while it was only $18.16 \%$ in JCMC which was similar to findings reported in study carried out by Khan et al. [10]. Majority of the patients $(79.53 \%)$ from the JCMC used both homemade as well as the commercial formulae for feeding purpose. Commercial formulae used alone as feeding purposes was recorded in very less population $(4.73 \%)$ among the patients admitted in JMCH and $1.84 \%$ in JCMC. Provision of total parental nutrition to majority of the patients both in JMCH $(89.94 \%)$ and JCMC (93.06\%) were found as the primary patient treatment regimen. Administration of Supplemental parenteral feeding was recorded in patient of latter feeding days to compensate for temporary reduction in the amount of daily enteral feeding due as some complications coming up during long term feeding of enteral feeding or to met the extra demand of the patients. The common oral food homemade blenderdised foods used for enteral feeding to the patients were rice gruel, soft rice, dal soup, khichidi, vegetable soup, dalia, fruit juice both the fresh and terta packed, roti, biscuits, rice and curry, boiled egg, pithaguri(rice flour), bread, apple, cake, maggi, glucose, horlicks, cerelac and milk etc. Out of these foods, for enteral feeding homemade blederdised food like khichidi, dal, soup, vegetable soup, fruit juices etc. were mostly used among the lower income population. Among the commercially available formulae in the market, Pentasure DM, Pentasure Balance, Pentasure HP, Bio-power, Ensure, Hepapro, Amiacael and Kabipro etc, were used for enteral feeding along with the homemade foods by well to do population.

Table 3. Distribution of Patients According to the Feeding Practices

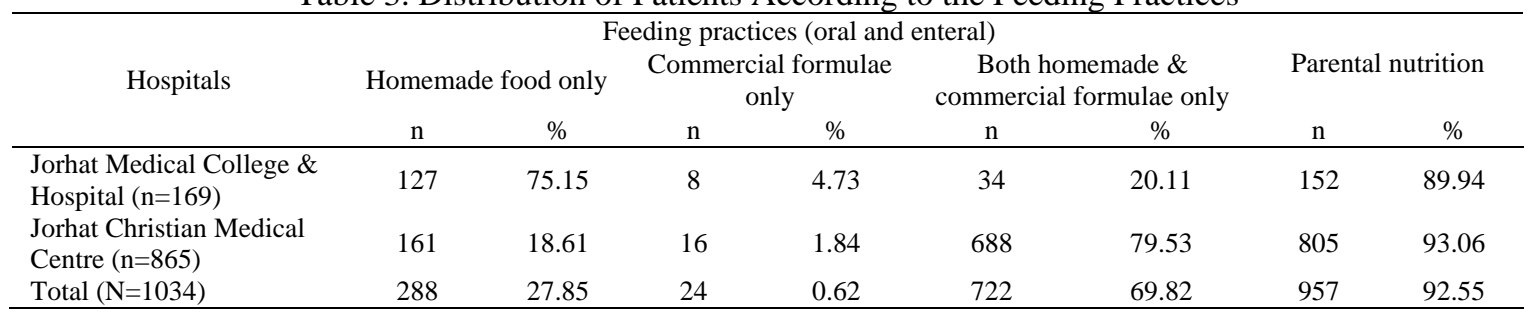

The length of stay of admitted cases in ICUs was evaluated from the day admitted to ICUs to the discharge day from ICUs (Figure 1) and it was found that majority $(54.43 \%$ ) of patient admitted to JMCH stayed for a duration of 10-15 days while 66.13 per cent of patients from private hospital (JCMC) stayed 6-10 days being a mean of $8.34+2.5$ days for the whole population. The mean LOS for individuals ICUs episodes in different studies reveals comparatively lower mean Los range of 4to 67 days [9],[11]-[13] and higher 
range of 13.4 to 15.2 days [7]. There were no significant relation between the disease diagnosed and length of stay $(\mathrm{p}=0.05)$. Longer length of stay (LOS) has been described among the patients admitted to Government hospital resulting in adverse outcomes and increased health costs cooperatively in case of patient admitted to private hospitals [14],[15]. Intensive cares in the ICUs along with use of commercially available supplements timely in private hospital were one of the reason for short stay in ICUs.

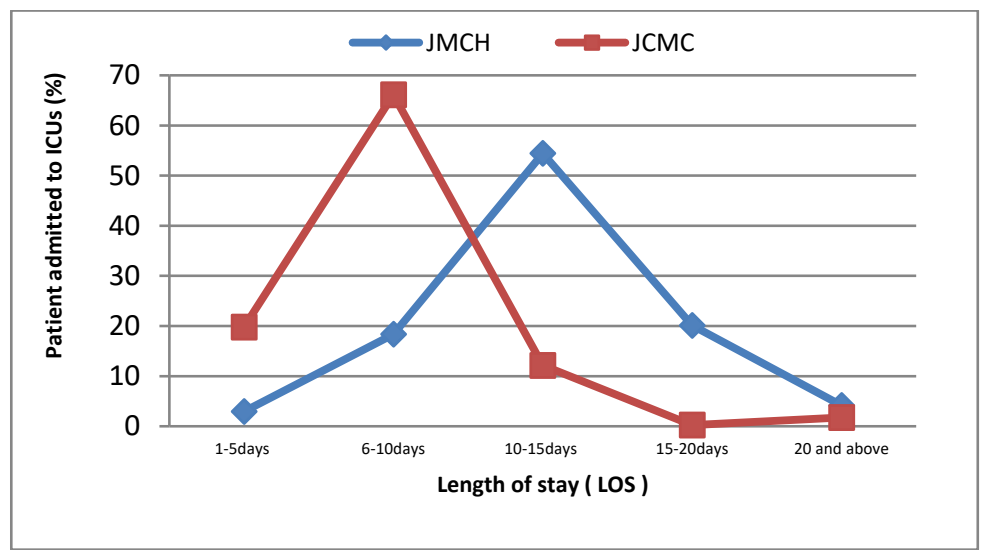

Figure 1. Distribution of patients according to length of stay at ICU

\section{CONCLUSION}

The findings of the present study showed shorter stay and better nutritional outcome among patients of private hospital compared with the patients admitted in government hospitals which may be due to the professional intensive care and use of commercially available products along with homemade foods. However, many patients have to depend on homemade foods or foods supplied from the hospital kitchen. The results of the present study will help in fulfilling the need for formulation and development of patient specific homemade foods taking accounts of the ingredients used and nutritional requirement of both oral and enteral feedings in the hospital. Consideration of all possible safety protocol during formulation and feeding practices will help to use these homemade foods at par with the commercially available formulae for nutritional support.

\section{REFERENCES}

[1] Wunsch H., et al., "Variation in critical care services across North America and Western Europe," Crit Care Med., vol. 17, pp. 2787-2793, 2008.

[2] R. Miranda D., et al., "Intensive care units in de landen van de Europese Gemeenschap," Medisch Contact, vol. 17, pp. 921-925, 1997.

[3] Jacobs P. and Noseworthy T. W., "National estimates of intensive care utilization and costs: Canada and the United States," Crit Care Med., vol. 17, pp. 1282-1286, 1990.

[4] Sirio C. A., et al., "A cross-cultural comparison of critical care delivery: Japan and the United States," Chest, vol. 17, pp. 539-548, 2002.

[5] B. Du, et al., "Characteristics of critically ill patients in patients in ICUs in mainland China," Crit. Care Med., vol. 38, pp. 2311-8, 2010.

[6] M. Maniou, "Measurement of patients' admissions to an intensive care unit of crete," Health science Journal, vol/issue: 3(3), pp. 469-478, 2012.

[7] M. H. Sherine, et al., "Predictors of hospital length of stay among Egyptian Elderly," Life Sci. J., vol/issue: 10(4), pp. 166-170, 2013.

[8] J. Belayachi, et al., "Factors predicting mortality in elderly patients admitted to a Moroccan medical intensive c are unit," S. Afr. J. Crit. Care, vol/issue: 28(1), pp. 22-27, 2012.

[9] Garland A., et al., "Epidemiology critically till patients in intensive care unit: a population based observational study," Critical care, vol. 17, pp. R212, 2013.

[10] M. N. Khan, et al., "Development of energy dense cost effective ome made enteral feed for nasogastric feeding," Journal of Nursing and Health Science, vol/issue: 4(3), pp. 34-41, 2015.

[11] Weissman C., "Analysing intensive care unit length of stays data: problem and possible situations," Crit. Care Med., vol/issue: 25(9), pp. 1594-1600, 1997.

[12] Sprung C. L., et al., "Evaluation of triage for intensive care admission," Crit. Care Med., vol/issue: 27(2), pp. 1073-1079, 1999. 
[13] Borse R. T., et al., "Comparision of demographic, clinical, radiological characteristics and comorbidities in medichanically ventilates and non- vanyilated adult patients admitted in ICU with confirms diagnosis of influenza A (H1N1)," J. of the Assoc. of Physicians of India, vol. 61, pp. 17-25, 2013.

[14] M. D. S. Hubert, et al., "Risk factors predicting later functional decline in older hospitalized patients," Acta Clin. Belg., vol. 64, pp. 187-194, 2003.

[15] H. Umegaki and F. S. Ando, "Factors associated with long hospital stay in geriatric wards in Japan," Geriatr. Gerontol Int., vol. 3, pp. 120-127, 2003.

\section{BIOGRAPHIES OF AUTHORS}

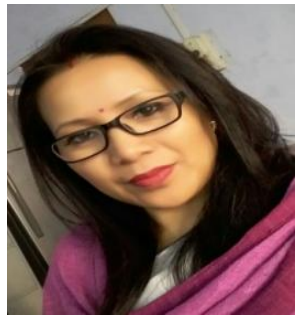

Premila L. Bordoloi

Assistant Professor, Department of Food Science and Nutrition Assam Agricultural University, Jorhat, Assam.

Phone Numbers : 0-8486039583

Email ID : premilajmch13@gmail.com

- Served as Research Associate in All Indian Co-ordinated Research Project for 10 years

- Served as Dietician for 5 years in Jorhat Medical College and Hospital, Jorhat, Assam.

- Working as Assistant Professor in Assam Agricultural University since 2015

- Publication :Research paper -3, Abstract -1, Book chapter, Poster presentation (2), Popular article -2

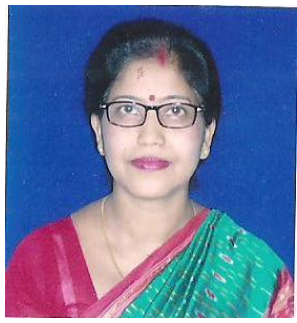

Dr. (Mrs) Mridula Saikia Barooah

Professor, In - charge Academic Cell Department of Food Science and Nutrition, College of Home Science, Assam Agricultural University, Jorhat-785013

Mobile no: 9435050682

E.mail ID: msbarooah@gmail.com

- No of students guided: M. Sc - 15 ( Ongoing -3) , Ph. D- 1 ( ongoing -2)

- Research projects completed:

- 1. " ICMR Co-ordinated scheme on Sub Clinical Vitamin A deficiency among children (671months) of Assam and Rajasthan" Duration: 6 months (2006)

- 2. " Standardization of selected Ethnic fermented foods and beverages by Rationalization of Indigenous knowledge" (NAIP-IV Component) Duration: 5 years (2009-2014).

- Training Experience: Conducted three months certificate course on bakery sponsored by USAID from $15^{\text {th }}$ December 2014 to $15^{\text {th }}$ march 2014.

- Publications ( Scientific papers and popular articles): Over 30 nos

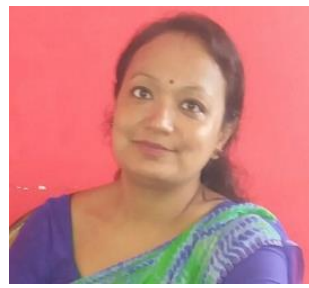

Moloya Gogoi

Assistant Professor, Department of Food Science and Nutrition, College of Home Science, Assam Agricultural University, Jorhat-785013

Mobile no: 07086893911

Email: moloyagog75@rediffmail.com

- Worked as Research Associate from April 2001 to $27^{\text {th }}$ November, 2008.under AICRP Home Science, Dept. of Food Science and Nutrition.

- Worked in the field of Research and Extension as Subject Matter Specialist from $28^{\text {th }}$ Nov 2008 to 06 July 2015.

- Presently working as Assistant Professor, Dept. of Food Science and Nutrition, Assam Agricultural University, Jorhat since July 2015.

- Publications (Numbers only):

- Research Papers: 7 General articles: 5 Book chapter:1 